\title{
EVALUASI DAN OPTIMALISASI KINERJA IPA I PDAM KOTA PONTIANAK
}

\author{
Rani Novitasari ${ }^{1}$, Isna Apriani, ST. M.Si ${ }^{1}$, Titin Anita Zahara, S.Si. M.Si ${ }^{2}$ \\ ${ }^{1}$ Program Studi Teknik Lingkungan, Fakultas Teknik, Universitas Tanjungpura, Pontianak \\ ${ }^{2}$ Program Studi Kimia, Fakultas MIPA, Universitas Tanjungpura, Pontianak \\ Email : enviro_rani@yahoo.com
}

\begin{abstract}
ABSTRAK
Perusahaan daerah air minum (PDAM) Tirta Khatulistiwa Pontianak merupakan salah satu perusahaan daerah yang bertanggungjawab dalam penyediaan air bersih di kota Pontianak. IPA I Imam Bonjol merupakan IPA yang paling tua di PDAM Kota Pontianak mempunyai kapasitas pengolahan sekitar 150 liter/detik yang mulai dioperasikan pada tahun 1962. Tujuan dari penelitian ini adalah mengetahui kualitas air baku dan air hasil produksi IPA I apakah sudah sesuai standar baku mutu menurut peraturan yang ada dan mengetahui efisiensi penyisihan di tiap unit pengolahan IPA I serta memberikan rekomendasi perbaikan. Metodologi yang digunakan adalah mengevaluasi kinerja IPA I berdasarkan kriteria desain dan menganalisa kualitas air baku dan air hasil produksi dengan standar baku mutu yang telah ditetapkan. Dari hasil penelitian bahwa air baku sungai Kapuas sudah memenuhi standar baku mutu air baku kelas I menurut PP.No. 82 Tahun 2001, tetapi untuk kekeruhan dan warna di atas baku mutu yaitu 39 NTU melebihi standar baku mutu 25 NTU dan warna 248 Pt.Co melebihi standar baku mutu 50 Pt.Co. Unit pengolahan IPA I terdiri dari koagulasi, flokulasi, sedimentasi, dan filtrasi. Pada unit koagulasi mempunyai efisiensi penyisihan kekeruhan $71,79 \%$ dan warna $72,89 \%$. Unit flokulasi efisiensi penyisihan kekeruhan $82,05 \%$ dan warna 87,90\%. Unit Sedimentasi efisiensi penyisihan kekeruhan 82,05\%, warna 91,13\% dan besi $95,55 \%$. Unit filtrasi efisiensi penyisihan kekeruhan $79,49 \%$, warna $91,53 \%$, dan besi 95,55\%. Air hasil produksi IPA I belum memenuhi standar baku mutu air minum menurut Peraturan Menteri Kesehatan Republik Indonesia No.492/MENKES/PER/1V/2010. Parameter yang belum sesuai standar baku mutu air minum adalah parameter warna, kekeruhan, aluminium. Parameter warna mempunyai konsentrasi 41,20 Pt.Co di atas standar baku mutu 15 Pt.Co, kekeruhan 7 NTU di atas standar baku mutu 5 NTU, aluminium $4 \mathrm{mg} / \mathrm{L}$ di atas standar baku mutu 0,2 mg/L. Parameter yang berada di bawah standar baku mutu adalah TDS, sulfat, dan besi. TDS mempunyai konsentrasi $110 \mathrm{mg} / \mathrm{L}$ di bawah standar baku mutu $1000 \mathrm{mg} / \mathrm{L}$, sulfat mempunyai konsentrasi $25 \mathrm{mg} / \mathrm{L}$ di bawah standar baku mutu 250 $\mathrm{mg} / \mathrm{L}$, besi mempunyai konsentrasi $0,03 \mathrm{mg} / \mathrm{L}$ di bawah standar baku mutu 0,3 $\mathrm{mg} / \mathrm{L}$. Secara keseluruhan kinerja unit pengolahan IPA I masih baik, tetapi pada unit flokulasi perlu adanya perbaikan untuk mengoptimalkan kinerja unit tersebut, yaitu dengan menambahkan baffle channel pada unit pengolahan sehingga kinerja di unit flokulasi dapat menjadi lebih baik.
\end{abstract}

Kata kunci : IPA, Air Baku, Efisiensi

\section{ABSTRACT}

PDAM Tirta Khatulistiwa Pontianak as a Local Water Supply Utility is one of the public utility which is responsibles for supplying clean water in Pontianak city. As the oldest Installationof water provision in Pontianak, IPA I Imam Bonjol has capacity about 150 litter/sec to provide water. It started operating in 1962. The purpose of this research is to identify the quality of raw water andtreated water from IPA I, are both appropriate tothe regulation about standard of raw water quality?, to know the removalefficiency in each installation of IPA I, and also to give recommendation of improvement. The methodology in this research is evaluates performance of IPA I based on criteria of design and to analizeraw waterquality and treated water qualityfrom PDAM due tostandard of raw water quality. Based on dataresearch, it is indicated thatraw water from Kapuas river is apropriateto the standard of raw waterquality, it placed in class I in PP.No.82 year 2001, but its turbidity reached 39 NTU higher than standard , 25 NTU and water color reached 248 Pt. Co higher than standard ,50 Pt.Co. Provision units of IPA I consist of coagulation, flocculation, sedimentation, and filtration. In coagulation unit, turbidity removalefficiency is about $71,79 \%$ and color about $72,89 \%$, in flocculation unit turbidity removal efficiency is about $82,05 \%$ and color $87,90 \%$. In sedimentation unit, turbidity removal efficiency is about 
$82,05 \%$ and color about $91,13 \%$ and iron about 95,55\%. In filtrationunit,turbidity removal efficiency is about $79,49 \%$, color about $91,53 \%$, and iron 95,55\%. The treated water produced by IPA I can't reach the minimum standard of raw water quality yet base on The Ministerof Health of the Republic of Indonesia regulation No.492/MENKES/PER/IV/2010. These parameters such as color, turbidity, and alumunium are not appropriate to standard of raw water quality yet. Parameter of color has concentration about 41,20 Pt.Co higher than standard of raw water quality 15 Pt.Co, turbidity about 7 NTU higher than standard 5 $N T U$, alumunium about $4 \mathrm{mg} / \mathrm{L}$ higher than standard 0,2 $\mathrm{mg} / \mathrm{L}$. TDS, sulfate, and iron have lower values than standard. TDS has concentration about $110 \mathrm{mg} / \mathrm{L}$ only from $1000 \mathrm{mg} / \mathrm{L}$ in standard, concentration of sulfate is about $25 \mathrm{mg} / \mathrm{L}$ under standard's value $0,3 \mathrm{mg} / \mathrm{L}$. Performance of provision unit of IPA I so far is well , but flocculation unit need to be improved to optimalize its performance by adding baffle channel at theprovision unit to make a better performance.

Keywords: IPA, Raw Water, Efficiency

\section{PENDAHULUAN}

Air merupakan salah satu faktor penting dalam penentuan kebutuhan manusia. Keberadaan air di muka bumi ini sangat berlimpah, mulai dari mata air, sungai, waduk, danau, laut, hingga samudera. Luas wilayah perairan lebih besar dari pada luas wilayah daratan. Walaupun demikian tidak seluruhnya dapat dimanfaatkan oleh manusia untuk memenuhi kebutuhan hidupnya. Salah satunya adalah kebutuhan akan air bersih dan air minum.

Perusahaan daerah air minum (PDAM) Tirta Khatulistiwa Pontianak merupakan salah satu perusahaan daerah yang bertanggungjawab dalam penyediaan air bersih di kota Pontianak. IPA I Imam Bonjol merupakan IPA yang paling tua di PDAM Kota Pontianak mempunyai kapasitas pengolahan sekitar 150 liter/detik yang mulai dioperasikan pada tahun 1962. Kualitas air baku di PDAM Kota Pontianak berdasarkan PP.82 Tahun 2001 dan kualitas air produksi berdasarkan Peraturan Menteri Kesehatan Republik Indonesia No.492/MENKES/PER/ IV/2010.

Selain itu, karena peningkatan jumlah penduduk dan kegiatannya yang mengakibatkan meningkatnya kebutuhan terhadap air minum. Karena keterbatasan kemampuan IPA tersebut, dari segi kualitas menjadikan kendala dalam memenuhi kebutuhan air minum di Kota Pontianak.

Berdasarkan hal tesebut, maka diperlukan suatu evaluasi kinerja di tiap unit IPA I PDAM Kota Pontianak, sehingga dapat memberikan optimalisasi dan masukan yang dianggap perlu dalam mengatasi permasalahan pada di tiap unit IPA I Imam Bonjol Kota Pontianak.

\section{TINJAUAN PUSTAKA}

Pada umumnya Instalasi Pengolahan Air minum merupakan suatu sistem yang mengkombinasikan proses koagulasi, flokulasi, sedimentasi, filtrasi, dan desinfeksi serta dilengkapi dengan pengontrolan proses juga instrument pengukuran yang dibutuhkan Instalasi ini harus didesain untuk menghasilkan air yang layak dikonsumsi masyarakat bagaimanapun kondisi cuaca dan lingkungan. Selain itu, sistem dan subsistem dalam instalasi yang akan didesain harus sederhana, efektif, dapat diandalkan, tahan lama, dan murah dalam pembiayaan (Kawamura, 1991).

Air permukaan merupakan salah satu sumber air minum yang banyak digunakan, terutama untuk instalasi pengolahan dengan kapasitas besar. Karakter umum dari air permukaan tergantung dari jenis sumbernya. Pada sungai, umumnya debit (kuantitas) dan kualitasnya bervariasi tergantung musim. Pada musim kemarau misalnya, airnya relatif jernih dengan debit yang menyusut. Beberapa sungai di Kalimantan dan Sumatera yang mendapat 
pasokan dari air rawa, seringkali mempunyai warna yang tinggi akibat adanya senyawa organik dan sisa-sisa tanaman yang terlarut (Anonim, 2005).

Standar kualitas air bersih dan minum yang berlaku di Indonesia saat ini adalah Peraturan Pemerintah Nomor 82 Tahun 2001 tanggal 14 Desember 2001 tentang Pengelolaan Kualitas Air dan Pengendalian Pencemaran Air serta Keputusan Menteri Kesehatan (Kepmenkes) RI No. 492/Menkes/Per/IV/2010.

\section{METODOLOGI PENELITIAN}

\section{A. Pengumpualan Data}

Pengumpulan data bertujuan untuk mendapatkan data yang diperlukan dan kemudian dilakukan analisa. Data yang dikumpulkan terdiri dari data primer dan sekunder.

\section{B. Pengambilan Sampel}

Pengambilan sampel air dilakukan pada Instalasi Pengolahan Air Minum (IPA I) di PDAM Pontianak Imam Bonjol, yaitu pada tanggal 7 Maret 2013 pada pukul 09.00 pagi. Lokasi pengambilan sampel air di instalasi pengolahan air dilakukan pada air baku dan air hasil olahan dari setiap unit pengolahan yang ada, hal ini bertujuan untuk mengetahui efisiensi setiap proses pengolahan yang ada di dalam instalasi. Terdapat 6 titik yang digunakan untuk mengambil sampel air yaitu : air baku, koagulasi, flokulasi, sedimentasi, filtrasi, dan air hasil produksi (desinfeksi).

\section{Analisa Kualitas Air Baku dan Air Hasil Produksi IPA I}

Analisa kualitas air baku dan kualitas hasil produksi meliputi parameter fisik dan kimiawi yaitu : kekeruhan, warna, TDS, Al, Fe, dan sulfat. Pengujian parameter di lakukan di Laboratorium Kesehatan Pontianak. Dari hasil tersebut di analisa dengan membandingkan parameter tersebut pada standar baku mutu air minum berdasarkan Peraturan Menteri Kesehatan No.492/Menkes/Per/IV/2010 dan standar baku mutu air baku kelas I menurut PP.No.82 Tahun 2001.

\section{Evaluasi Kinerja dan Optimalisasi IPA I}

Membandingkan kondisi esksisting instalasi dengan standar peraturan yang berlaku dan kriteria desain tiap unit. Metode yang digunakan pada instalasi berguna untuk mengetahui unit apa saja yang digunakan di instalasi. Dimensi unit akan dibandingkan dengan kriteria desain unit. Kualitas air pada proses pengolahan di instalasi di hitung efisiensi dari kinerja unit bangunan instalasi apakah masih berjalan dengan baik. Evaluasi dilakukan pada unit koagulasi, flokulasi, sedimentasi, filtrasi, dan reservoir (desinfeksi).

\section{ANALISIS DAN PEMBAHASAN}

\section{A. Kualitas Air Baku}

Air baku menurut Peraturan Menteri Kesehatan Republik Indonesia Nomor 16 Tahun 2005 adalah air yang digunakan sebagai sumber/bahan baku dalam penyediaan air bersih. Hasil kualitas air baku dan unit-unit pengolahan yang ada di instalasi pengolahan IPA I pada Tabel 1 Hasil Analisa Kualitas Air Baku PDAM Pontianak. 
Tabel 1. Hasil Analisa Kualitas Air Baku PDAM Pontianak

\begin{tabular}{llcccll}
\hline \multirow{2}{*}{ No } & \multirow{2}{*}{ Parameter analisis } & \multirow{2}{*}{ Satuan } & Baku Mutu & Titik sampling & \multirow{2}{*}{ Metode } \\
\cline { 5 - 6 } & & Kelas $\mathrm{I}^{*}$ ) & Air Baku & \\
\hline 1 & Kekeruhan & NTU & 25 & 39 & Turbiditimeter \\
2 & Warna & Pt.Co & 50 & 248 & Spectrofotometri \\
3 & Residu Terlarut(TDS) & $\mathrm{mg} / \mathrm{L}$ & 1000 & 22 & TDS meter \\
4 & Besi (Fe) & $\mathrm{mg} / \mathrm{L}$ & 1,0 & 0,09 & Sm Ed.21 Th. 2005 \\
5 & Sulfat (SO4) & $\mathrm{mg} / \mathrm{L}$ & 400 & 10 & Sm Ed.21 Th. 2006 \\
\hline
\end{tabular}

Keterangan :

*) Baku Mutu Kelas I berdasarkan Pemerintah Nomor 82 Tahun 2001 tentang Pengelolaan Kualitas Air dan Pengendalian Pencemaran Air.

Berdasarkan Tabel 1 air baku memiliki kekeruhan yang tinggi yaitu 39,00 NTU. Berdasarkan PP.No.82 Tahun 2001 menyatakan bahwa kadar maksimum kekeruhan yang diperbolehkan untuk baku mutu air kelas I yaitu 25 NTU. Air baku di PDAM Imam Bonjol Pontianak berasal dari Sungai Kapuas yang merupakan air permukaan. Air permukaan dengan tingkat kekeruhan rendah sampai sedang memiliki tingkat kekeruhan sekitar 10-50 NTU. Kekeruhan disebabkan oleh adanya bahan organik dan anorganik yang tersuspensi dan terlarut (misalnya lumpur dan pasir halus), maupun bahan anorganik dan organik yang berupa plankton dan mikroorganisme lain (APHA,1976; Davis dan Cornwell, 1991 dalam Effendi 2003).

Warna pada air baku sungai Kapuas memiliki nilai 248 Pt.Co. Nilai ini sangat cukup tinggi, dimana hal ini sesuai dengan kondisi air pada waktu pengambilan sampel yang berwarna cukup gelap kekuning-kuningan. Air yang berasal dari rawa-rawa yang biasanya berwarna kuning kecokelatan hingga kehitaman memiliki nilai warna sekitar 200-300 PtCo karena adanya asam humus (McNeely et al.,1979 dalam Tri Joko 2010). Konsentrasi warna pada standar baku mutu kelas I PP. No.82 Tahun 2001 adalah 50 NTU.

Total Dissolved Solid (TDS) pada air baku mempunyai nilai $22 \mathrm{mg} / \mathrm{L}$. Berdasarkan PP. No 82 Tahun 2001 standar baku mutu yaitu 1000 mg/L,sehingga konsentrasi TDS masih di bawah standar baku mutu.

Konsentrasi besi pada air baku adalah $0,09 \mathrm{mg} / \mathrm{l}$ dibawah standar baku mutu air baku menurut PP. No.82 Tahun 2001 yaitu 1 mg/L.

Konsentrasi sulfat pada perairan alami berkisar antara 2-80 mg/L (Effendi, 2003). Konsentrasi sulfat pada air baku adalah $10 \mathrm{mg} / \mathrm{L}$. Konsentrasi standar batas maksimal untuk air baku yang ditetapkan PP.No.82 Tahun 2001 adalah 400 mg/L.

\section{B. Evaluasi Kinerja di Unit IPA I}

\section{Koagulasi}

Proses koagulasi adalah penambahan dan pengadukan cepat (Flash mixing) koagulan yang bertujuan untuk mendestabilisasi partikel-partikel koloid dan suspended solid (Reynold, 1982). Koagulasi di IPA I secara hidrolis memanfaatkan tekanan dari pompa. Air baku di pompakan melalui pipa, kemudian air disemburkan ke dalam bak koagulasi, sehingga bahan kimia dapat terakumulasi atau tercampur dengan baik. Koagulasi IPA I mempunyai dimensi Panjang 2,10 m, lebar 1,60 m, dan tinggi bak 1,25 m. Pompa yang digunakan 2 buah dengan kapasitas pompa 150 L/detik. Walaupun tidak dapat ditentukan gradient kecepatan dan waktu detensinya, secara 
penglihatan di lapangan menunjukkan proses koagulasi IPA I sudah berjalan dengan baik. Walaupun tidak dapat ditentukan gradient kecepatan dan waktu detensinya, secara penglihatan di lapangan menunjukkan proses koagulasi IPA I sudah berjalan dengan baik. Kualitas air dan efisiensi penyisihan di unit koagulasi dapat dilihat pada Tabel 2.

Tabel 2. Kualitas Air dan Efisiensi Penyisihan di Unit Koagulasi

\begin{tabular}{llccccl}
\hline \multirow{2}{*}{ No } & Parameter & Satuan & \multicolumn{2}{c}{ Kualitas air } & \multirow{2}{*}{$\begin{array}{c}\text { Efisiensi } \\
\text { Penyisihan }\end{array}$} & Metode \\
\cline { 3 - 4 } & & Air Baku & Koagulasi & $(\%)$ & \\
\hline 1 & Kekeruhan & NTU & 39,00 & 11,00 & 71,79 & Turbiditimeter \\
2 & Warna & Pt.Co & 248,00 & 67,00 & 72,89 & Spectrofotometri \\
\hline
\end{tabular}

Berdasarkan Tabel 2 diatas dapat dilihat kualitas air di unit koagulasi dan efisiensi penyisihan di unit koagulasi, untuk parameter kekeruhan mempunyai efisiensi penyisihan sebesar $71,79 \%$ dan warna $72,98 \%$.

\section{Flokulasi}

Flokulasi pada IPA I hanya hanya menggunakan bak berbentuk persegi panjang dengan sekat di kedua sisinya. Waktu detensi flokulasi adalah 11 menit. Flokulasi sebaiknya dilakukan selama 30-40 menit (Kawamura,1991). Untuk mengoptimalkan proses flokulasi dapat dirancang unit flokulasi dengan penambahan baffle channel secara vertikal. Hasil perhitungan headloss pada flokulasi dapat dilihat pada Tabel 3.

Tabel 3. Hasil Perhitungan Headloss Flokulasi pada Baffle Channel

\begin{tabular}{cccc}
\hline \multirow{2}{*}{ Tahap } & Gradien & Waktu detensi (Td) & Headloss (hL) \\
\cline { 2 - 4 } & (Liter/detik) & (detik) & (m) \\
\hline 1 & 60 & 360 & 0,118 \\
2 & 50 & 360 & 0,082 \\
3 & 40 & 360 & 0,052 \\
4 & 30 & 360 & 0,029 \\
5 & 20 & 360 & 0,013 \\
\hline \multicolumn{5}{c}{ hL Total } & 0,294 \\
\hline
\end{tabular}

Kualitas air dan efisiensi penyisihan pada proses flokulasi dapat dilihat pada Tabel 4.

Tabel 4. Kualitas Air dan Efisiensi Penyisihan di Unit Flokulasi

\begin{tabular}{|c|c|c|c|c|c|c|}
\hline \multirow{2}{*}{ No } & \multirow{2}{*}{ Parameter } & \multirow{2}{*}{ Satuan } & \multicolumn{2}{|c|}{ Kualitas air } & \multirow{2}{*}{$\begin{array}{c}\text { Efisiensi } \\
\text { Penyisihan } \\
(\%) \\
\end{array}$} & \multirow{2}{*}{ Metode } \\
\hline & & & Air Baku & Flokulasi & & \\
\hline 1 & Kekeruhan & NTU & 39,00 & 7,00 & 82,05 & Turbiditimeter \\
\hline 2 & Warna & Pt.Co & 248,00 & 30,00 & 87,90 & Spectrofotometri \\
\hline
\end{tabular}

Dapat dilihat pada Tabel 4, efisiensi penyisihan untuk parameter kekeruhan 82,05\% dan warna $87,90 \%$. Keberhasilan penyisihan warna sangat ditentukan oleh proses tumbukan antara partikel koloid yang telah dikoagulasi, sehingga mampu membentuk partikel flok yang berukuran lebih besar dan kompak, sehingga mudah diendapkan (Lindu, 2001 dalam Rizal Amir 2010). 
Proses flokulasi IPA I sudah efisien dalam menurunkan parameter kekeruhan dan warna, namun waktu detensi dan bangunan dari flokulasi perlu ada nya perbaikan untuk mengoptimalkan kinerja dari proses flokulasi.

\section{Sedimentasi}

Berdasarkan hasil perhitungan, nilai surface loading rate atau beban permukaan bak sedimentasi pada saat normal dan pengurasan telah sesuai dengan kriteria desain yaitu 77,88 $\mathrm{m}^{3} / \mathrm{m}^{2}$.hari dan $83,07 \mathrm{~m}^{3} / \mathrm{m}^{2}$.hari $\left(<150 \mathrm{~m}^{3} / \mathrm{m}^{2}\right.$.hari). Beban permukaan (surface loading) yaitu debit aliran per unit area permukaan bak pengendap. Kecepatan mengendap partikel adalah sama dengan beban permukaan, dan ini berarti tidak ada ketergantungan dengan kedalaman bak sedimentasi (Tri Joko, 2010).

Dari hasil perhitungan diketahui nilai Reynold pada saat normal 23,29 dan saat pengurasan 24,63. Dari hasil tersebut aliran laminer sesuai dengan kriteria desain ( $R e<2000$ ) sehingga pengendapan dapat terjadi. Unit sedimentasi membutuhkan kondisi aliran yang laminer untuk menjamin terjadinya pengendapan (Hadisoebroto dan Notodarmojo, 2004). Laju pengendapan flok merupakan salah satu faktor terpenting, tidak hanya untuk desain agar pengoperasian instalasi pengolahan menjadi efektif tetapi juga untuk memprediksi dispersi partikel tersuspensi (Adachi dan Tanaka, 1997 dalam Euis 2010).

Kecepatan horizontal partikel pada nilai Fr tidak sesuai dengan kriteria desain didapat lebih dari $10^{-5}$ yaitu pada saat normal 2,05 × 10-7 dan saat pengurasan $6,1 \times 10^{-6}$. Untuk menurunkan nilai $\mathrm{Fr}$ dapat dilakukan dengan mengubah kemiringan settler atau mengganti ukuran settler. Dari data eksisting jumlah plate settler adalah 286 buah dengan nilai Froude belum sesuai dengan kriteria, setelah adanya penambahan plate settler 347 buah bilangan Froude menjadi $1,1 \cdot 10^{-5}$ telah sesuai dengan kriteria $>10^{-5}$. Waktu detensi bak saat normal atau pengurasan masih sesuai dengan kriteria desain yaitu 6,47 menit dan 6,06 menit ( $<120$ menit). Kualitas air dan efisiensi penyisihan pada proses sedimentasi mengacu pada Tabel 5.

Tabel 5. Kualitas Air dan Efisiensi Penyisihan di Unit Sedimentasi

\begin{tabular}{|c|c|c|c|c|c|c|}
\hline \multirow{2}{*}{ No } & \multirow{2}{*}{ Parameter } & \multirow{2}{*}{ Satuan } & \multicolumn{2}{|c|}{ Kualitas air } & \multirow{2}{*}{$\begin{array}{c}\text { Efisiensi } \\
\text { Penyisihan } \\
\text { (\%) }\end{array}$} & \multirow{2}{*}{ Metode } \\
\hline & & & Air Baku & Sedimentasi & & \\
\hline 1 & Kekeruhan & NTU & 39,00 & 7,00 & 82,05 & Turbiditimeter \\
\hline 2 & Warna & Pt.Co & 248,00 & 22,00 & 91,13 & $\begin{array}{l}\text { Spectrofotometri } \\
\text { Sm Ed.21 Th. }\end{array}$ \\
\hline 3 & Besi & $\mathrm{mg} / \mathrm{L}$ & 0,90 & 0,04 & 95,55 & 2005 \\
\hline
\end{tabular}

Salah satu fungsi dari bangunan sedimentasi adalah menyingkirkan partikel yang terkandung di dalam air berupa partikel yang sudah terkoagulasi seperti kekeruhan dan warna serta hasil endapan dari proses presipitasi seperti besi (Tri Joko, 2010). Berdasarkan Tabel 5, dapat dilihat efisiensi penyisihan untuk parameter kekeruhan $82,05 \%$, warna $91,13 \%$, dan besi $95,55 \%$. Proses sedimentasi IPA I sudah efisien dalam menurunkan parameter kekeruhan, warna dan besi.

\section{Filtrasi}

Dari hasil perhitungan diketahui bahwa lebar dan rasio panjang dan lebar bak filter dan kedalaman bak sudah sesuai dengan kriteria desain yaitu $2: 1$ dengan kedalaman bak $5 \mathrm{~m}$. Luas 
permukaan bak filter tidak sesuai dengan kriteria desain, sehingga perlu penambahan dimensi panjang dan lebar pada bak filtrasi agar luas permukaan memenuhi kriteria desain. Luas area $22,5 \mathrm{~m}^{2}<\left(25-80 \mathrm{~m}^{2}\right)$. Waktu operasi sudah sesuai dengan kriteria yaitu $24 \mathrm{jam}$. Pencucian dengan backwash dilakukan 3 bulan sekali, namun pada saat terjadi clogging minimal dilakukan pencucian 1 kali sehari.

Kecepatan filtrasi sudah sesuai dengan kriteria desain. Kecepatan filtrasi pada saat normal adalah $112,32 \mathrm{~m}^{3} / \mathrm{m}^{2}$.hari dan saat pengurasan $192 \mathrm{~m}^{3} / \mathrm{m}^{2}$.hari lebih dari $\left(100-475 \mathrm{~m}^{3} / \mathrm{m}^{2}\right.$.hari). Kecepatan filtrasi merupakan parameter kunci yang digunakan untuk menentukan luas permukaan bak. Semakin besar kecepatan filtrasi maka luas bak yang dibutuhkan semakin kecil (Anderson, 2012). Unit filtrasi ini juga dapat bekerja dengan baik saat backwash (2 unit tidak beroperasi) karena nilai kecepatan filtrasi pada saat backwash berdasarkan perhitungan diatas masih sesuai dengan kriteria desain.

Tebal media filter telah sesuai dengan kriteria desain dengan tebal $60 \mathrm{~cm}(60-80 \mathrm{~cm})$ menggunakan single media dengan media pasir. Partikel tersuspensi yang terdapat pada influen akan tertahan pada permukaan filter karena adanya mekanisme filtrasi. Oleh karena itu, efisiensi filter merupakan fungsi karakteristik dari filter bed, yang meliputi porositas dari ratio kedalaman media terhadap ukuran media. Tebal tidaknya media akan mempengaruhi lama pengaliran dan besar daya saring (Edahwati,2009). Headloss pada media saringan 0,28 $\mathrm{m}(0,2-3 \mathrm{~m})$ masih sesuai dengan kriteria desain. Untuk $\mathrm{hL}$ pada underdrain tidak dapat dihitung karena tidak ada data dimensi dan jumlah lubang.

Kehilangan tekan (Headloss) pada saat backwash tidak dapat dihitung karena tidak ada data kecepatan backwash maupun debit backwash. Kualitas air dan efisiensi penyisihan pada proses filtrasi mengacu pada Tabel 6.

Tabel 6. Kualitas Air dan Efisiensi Penyisihan di Unit Filtrasi

\begin{tabular}{llccccl}
\hline \multirow{2}{*}{ No } & Parameter & Satuan & \multicolumn{2}{c}{ Kualitas air } & \multirow{2}{*}{$\begin{array}{c}\text { Efisiensi } \\
\text { Penyisihan }\end{array}$} & Metode \\
\cline { 3 - 5 } & & Air Baku & Filtrasi & & $(\%)$ & \\
\hline 1 & Kekeruhan & NTU & 39,00 & 8,00 & 79,49 & Turbiditimeter \\
2 & Warna & Pt.Co & 248,00 & 21,00 & 91,53 & Spectrofotometri \\
3 & Besi & mg/L & 0,90 & 0,04 & 95,55 & Sm Ed.21 Th. 2005 \\
\hline
\end{tabular}

Filtrasi diperlukan untuk menyempurnakan penurunan kadar kontaminan seperti kekeruhan, warna, dan Fe (Tri Joko, 2010). Berdasarkan Tabel 6 dapat dilihat efisiensi penyisihan kekeruhan $79,49 \%$, warna $91,53 \%$, dan besi $95,55 \%$. Proses filtrasi IPA I sudah efisiensi dalam menurunkan parameter kekeruhan, warna dan besi.

\section{Desinfeksi}

Desinfektan yang digunakan adalah gas klor, dan masih berfungsi dengan baik. Kontak desinfeksi terjadi di dalam reservoar air bersih. Pembubuhan dilakukan dengan dosering pump dari ruang gas klor menuju inlet reservoar air bersih secara continue. Dosis klor yang digunakan untuk IPA I dengan kapasitas $150 \mathrm{~L} /$ detik adalah 0,0014 kg/detik atau 1,40 gr/detik dengan kadar murni 99\%. Dikarenakan bersifat gas, sehingga pembubuhan langsung di dalam pipa menuju reservoir, agar gas tidak terakumulasi dengan udara. Sisa klor di reservoir (PDAM, 2013) adalah rata-rata $0,17 \mathrm{mg} / \mathrm{L}$ di bawah standar baku mutu air minum menurut Peraturan Menteri Kesehatan Republik Indonesia No. 492/MENKES/PER/2010 yaitu 5 mg/L. 


\section{Reservoir}

Dari hasil perhitungan jumlah kompartemen hanya 1 buah sehingga tidak sesuai dengan kriteria desain seharusnya memiliki 2 unit. Kedalaman reservoir hanya $2 \mathrm{~m}$, sehingga perlu adanya peambahan dimensi pada kedalaman (tinggi). Waktu tinggal direservoir 2,7 jam belum sesuai dengan kriteria desain $<1$ jam. Volume optimal adalah $1000 \mathrm{~m}^{3}$ dengan 2 kompartemen sehingga masing-masing $500 \mathrm{~m}^{3}$, dengan demikian waktu tinggal di reservoir menjadi $<1$ jam (sesuai dengan kriteria desain).

\section{Air Hasil Produksi}

Kualitas air produksi dan efisiensi penyisihan dapat dilihat pada Tabel 7.

Tabel 7. Kualitas Air dan Efisiensi Penyisihan Hasil Produksi

\begin{tabular}{|c|c|c|c|c|c|c|}
\hline \multirow[b]{2}{*}{ No } & \multirow[b]{2}{*}{ Parameter } & \multirow[b]{2}{*}{ Satuan } & \multirow{2}{*}{$\begin{array}{c}\text { Standar } \\
\text { Baku } \\
\text { Mutu*) }\end{array}$} & \multicolumn{2}{|c|}{ Kualitas air } & \multirow[b]{2}{*}{ Metode } \\
\hline & & & & Air Baku & Produksi & \\
\hline 1 & Kekeruhan & NTU & 5 & 39,00 & 7,00 & Turbiditimeter \\
\hline 2 & Warna & Pt.Co & 15 & 248,00 & 41,20 & Spectrofotometri \\
\hline 3 & Aluminium & $\mathrm{mg} / \mathrm{L}$ & 0,2 & 0,29 & 4,00 & Spectrofotometri \\
\hline 4 & Besi & $\mathrm{mg} / \mathrm{L}$ & 0,3 & 0,09 & 0,03 & Sm Ed.21 Th. 2005 \\
\hline 5 & Sulfat & $\mathrm{mg} / \mathrm{L}$ & 250 & 10,00 & 25,00 & Sm Ed.21 Th. 2006 \\
\hline 6 & TDS & $\mathrm{mg} / \mathrm{L}$ & 1000 & 22,00 & 110,00 & TDS meter \\
\hline
\end{tabular}

Keterangan :

*) Baku Mutu berdasarkan Peraturan Menteri Kesehatan Republik Indonesia No.492/MENKES/PER/1V/2010

Pada Tabel 7 diatas, parameter kekeruhan mempunyai konsentrasi 7 NTU dan warna 41,20 Pt.Co. Berdasarkan standar baku mutu air minum menurut Peraturan Menteri Kesehatan Republik Indonesia No.492/MENKES/PER/2010, parameter kekeruhan 5 NTU dan warna 15 NTU, sehingga air produksi belum memenuhi standar baku mutu tersebut. Untuk parameter besi mempunyai konsentrasi $0,03 \mathrm{mg} / \mathrm{L}$ dibawah standar baku mutu untuk air minum menurut Peraturan Menteri Kesehatan Republik Indonesia No. 492/MENKES/PER/2010 yaitu 0,3 mg/L.

Untuk parameter aluminium, sulfat, dan TDS mengalami kenaikan konsentrasi. Parameter aluminium mempunyai konsentrasi $4 \mathrm{mg} / \mathrm{L}$ di atas standar baku mutu air minum 0,2 mg/L. Parameter sulfat mempunyai konsentrasi $25 \mathrm{mg} / \mathrm{L}$ dibawah standar baku mutu air minum 250 $\mathrm{mg} / \mathrm{L}$. Parameter TDS mempunyai konsentrasi $110 \mathrm{mg} / \mathrm{L}$ dibawah standar baku mutu air minum yaitu $1000 \mathrm{mg} / \mathrm{L}$.

Konsentrasi TDS meningkat pada unit reservoir air hasil produksi karena terjadi penambahan gas klor pada unit desinfeksi sebelum masuk ke reservoir (Aprian, 2010). Kehadiran senyawa organik juga diketahui sebagai tanda adanya senyawa karsinogenik dan mutagenik trihalometan umumnya dalam proses pengolahan air minum konvensional, yang menggunakan proses klorinasi (Rook, 1974; Singer, 1999; Uyguner dan Bekbolet, 2008 dalam Aprian, 2010). 


\section{PENUTUP}

A. Kesimpulan

1. Air baku yang digunakan PDAM Kota Pontianak pada IPA I sudah memenuhi standar baku mutu untuk air baku kelas I menurut PP.No. 82 Tahun 2001. Parameter TDS 22 $\mathrm{mg} / \mathrm{L}$ di bawah standar baku mutu $1000 \mathrm{mg} / \mathrm{L}$, besi $0,09 \mathrm{mg} / \mathrm{L}$ di bawah standar baku mutu $1,0 \mathrm{mg} / \mathrm{L}$ dan sulfat $10 \mathrm{mg} / \mathrm{L}$ di bawah standar baku mutu $400 \mathrm{mg} / \mathrm{L}$. Tetapi untuk parameter warna $248 \mathrm{Pt}$.Co di atas standar baku mutu 50 Pt.Co dan kekeruhan 48 NTU di atas standar baku mutu 25 NTU.

2. Air hasil produksi IPA I belum memenuhi standar baku mutu air minum menurut Peraturan Menteri Kesehatan Republik Indonesia No.492/MENKES/PER/1V/2010. Parameter yang belum sesuai standar baku mutu air minum adalah parameter warna, kekeruhan, aluminium. Parameter warna mempunyai konsentrasi 41,20 Pt.Co di atas standar baku mutu 15 Pt.Co, kekeruhan 7 NTU di atas standar baku mutu 5 NTU, aluminium $4 \mathrm{mg} / \mathrm{L}$ di atas standar baku mutu $0,2 \mathrm{mg} / \mathrm{L}$. Parameter yang berada di bawah standar baku mutu adalah TDS, sulfat, dan besi. TDS mempunyai konsentrasi $110 \mathrm{mg} / \mathrm{L}$ di bawah standar baku mutu $1000 \mathrm{mg} / \mathrm{L}$, sulfat mempunyai konsentrasi 25 $\mathrm{mg} / \mathrm{L}$ di bawah standar baku mutu $250 \mathrm{mg} / \mathrm{L}$, besi mempunyai konsentrasi 0,03 mg/L di bawah standar baku mutu $0,3 \mathrm{mg} / \mathrm{L}$.

3. Hasil evaluasi kinerja IPA I adalah : unit koagulasi mempunyai efisiensi penyisihan 71,79\% dan warna 72,89\%. Unit flokulasi efisiensi penyisihan kekeruhan 82,05\% dan warna $87,90 \%$. Unit sedimentasi efisensi penyisihan kekeruhan $82,05 \%$, warna $91,13 \%$, dan besi $95,55 \%$. Unit filtrasi efisiensi penyisihan kekeruhan 79,49\%, warna $91,53 \%$, dan besi $95,55 \%$.

4. Secara keseluruhan kinerja unit pengolahan IPA I masih baik, tetapi pada unit flokulasi perlu adanya perbaikan untuk mengoptimalkan kinerja unit tersebut, yaitu dengan menambahkan baffle channel pada unit pengolahan sehingga kinerja di unit flokulasi menjadi lebih baik.

\section{Ucapan Terima Kasih}

Dalam kesempatan ini, penulis menyampaikan terima kasih yang sebesar-besarnya kepada : Ibu Titin Anita Zahara,S.Si.,M.Si., selaku Dosen Pembimbing Utama, Ibu Isna Apriani, ST.,M.Si., selaku Dosen Pembimbing Pendamping serta kepada Dosen Penguji Ibu Ir.Hj.Kartini, MT dan Ibu Rizki Purnaini, ST.,MT sebagai penguji utama dan penguji pendamping.

\section{Referensi}

Amir, R., \& Isnaniawardhana, J.N. 2010. Penentuan Dosis Optimum Aluminium Sulfat Dalam Pengolahan Air Kali Cileulueur Kota Ciamis dan Pemanfaatan Resirkulasi Lumpur dengan Parameter pH, Warna, Kekeruhan dan TSS. Program Studi Teknik Lingkungan, Fakultas Teknik Sipil dan Lingkungan, Institut Teknologi Bandung. (http://www.ftsl.itb.ac.id Diakses pada tanggal 15 Mei 2013)

Anonim. 2005. Kursus Singkat Teknologi Pengolahan Air dan Pemantauan Kualitas Air Departemen Teknik Lingkungan ITB Bekerjasama dengan LAPI ITB, PDAM: Kota Pontianak. 
Edahwati, Luluk. 2000. Kombinasi Proses Aerasi, Adsorpsi, dan Filtrasi pada Pengolahan Air Limbah Industri Perikanan. Jurnal Teknik Lingkungan : 7983.(http://eprints.upnjatim.ac.id/1244/2/(6)_Luluk_edahwati.pdf diakses pada tanggal 19 September 2013)

Edwardo, Anderson; Darmatyanti, Lita; \& Rinaldi. 2012. Jurnal ilmiah teknik sipil Vol. 1 No. 1 Pengolahan Air Gambut dengaan Media Filter Batu Apung. Program Studi Teknik Sipil S1, Fakultas Teknik Universitas Riau. (http://repository.unri.ac.id diakses tanggal 15 Mei 2013)

Effendi, H. 2003. Telaah Kualitas Air Bagi Pengolahan Sumberdaya Hayati Lingkungan Perairan. Yogyakarta: Kanysius.

Hadisoebroto. R., dan S. Notodarmojo. 2004. Pengaruh Debit Influen Terhadap Karakteristik Hidrodinamika Kolam Fakultatif Bojongsoang : Tanpa Pengaruh Angin. Makara Teknologi,Vol.8,No.3:Hal.83(http://journal.ui.ac.id/index.php/technology/article/view/ 270/266 diakses pada tanggal 19 September 2013).

Hidayah, Euis Nurul. 2010. Penerapan Model HP2S (Hidrodinamika Penyebaran Polutan Di Sungai Terhadap Pola Pengendapan Flok Pada Proses Sedimentasi. Master Theses Teknik Manajemen Lingkungan S2, Institut Teknologi Surabaya. (http://digilib.its.ac.id diakses tanggal 15 Mei 2013).

Joko, Tri. 2010. Unit Air Baku Dalam Sistem Penyediaan Air Minum.Yogyakarta: Graha Ilmu

Kawamura. 1991. An Integrated Calculation of Wastewater Engineering. New York : John Wiley \& Sons.

KEPMENKES Republik Indonesia Nomor: No. 492/Menkes/Per/IV/2010. Tentang Persyaratan Kualitas Air Minum.

Peraturan Pemerintah Republik Indonesia No. 82 tahun 2001. Tentang Pengelolaan Kualitas Air dan Pengendalian Pencemaran Air.

Rahadi, Eka Aprian; Kardena, Edwan. 2010. Kualitas Air Pada Proses Pengolahan Air Minum Di Instalasi Pengolahan Air Minum Lippo Cikarang. Program Studi Teknik Lingkungan, Fakultas Teknik Sipil dan Lingkungan, Institut Teknologi Bandung. (http://www.ftsl.itb.ac.id diakses tanggal 15 Mei 2013)

Reynolds. 1982. Unit Operations and Processes In Environmental Engineering, California: Wadsworth, Inc

Saputri, Afrike Wahyuni. 2011. Evaluasi Instalasi Pengolahan Air Minum (IPA) Babakan PDAM Tirta Kerta Raharja Kota Tangerang, Fakultas Teknik Program Studi Teknik Lingkungan Depok FT.UI (http://lontar.ui.ac.id diakses tanggal 15 Mei 2013) 